\title{
Validation and update of OMI Total Column Water Vapor product
}

\author{
Huiqun Wang, Gonzalo Gonzalez Abad, Xiong Liu, and Kelly Chance \\ Smithsonian Astrophysical Observatory, Cambridge, Massachusetts, 02421, USA \\ Correspondence to: Huiqun Wang (hwang@cfa.harvard.edu) \\ Received: 1 March 2016 - Published in Atmos. Chem. Phys. Discuss.: 18 April 2016 \\ Revised: 6 July 2016 - Accepted: 24 August 2016 - Published: 14 September 2016
}

\begin{abstract}
The collection 3 Ozone Monitoring Instrument (OMI) Total Column Water Vapor (TCWV) data generated by the Smithsonian Astrophysical Observatory's (SAO) algorithm version 1.0 and archived at the Aura Validation Data Center (AVDC) are compared with NCAR's ground-based GPS data, AERONET's sun-photometer data, and Remote Sensing System's (RSS) SSMIS data. Results show that the OMI data track the seasonal and interannual variability of TCWV for a wide range of climate regimes. During the period from 2005 to 2009, the mean OMI-GPS over land is $-0.3 \mathrm{~mm}$ and the mean OMI-AERONET over land is $0 \mathrm{~mm}$. For July 2005, the mean OMI-SSMIS over the ocean is $-4.3 \mathrm{~mm}$. The better agreement over land than over the ocean is corroborated by the smaller fitting residuals over land and suggests that liquid water is a key factor for the fitting quality over the ocean in the version 1.0 retrieval algorithm. We find that the influence of liquid water is reduced using a shorter optimized retrieval window of $427.7-465 \mathrm{~nm}$. As a result, the TCWV retrieved with the new algorithm increases significantly over the ocean and only slightly over land. We have also made several updates to the air mass factor (AMF) calculation. The updated version 2.1 retrieval algorithm improves the land/ocean consistency and the overall quality of the OMI TCWV data set. The version 2.1 OMI data largely eliminate the low bias of the version 1.0 OMI data over the ocean and are $1.5 \mathrm{~mm}$ higher than RSS's "clear" sky SSMIS data in July 2005. Over the ocean, the mean of version 2.1 OMI-GlobVapour is $1 \mathrm{~mm}$ for July 2005 and $0 \mathrm{~mm}$ for January 2005. Over land, the version 2.1 OMI data are about $1 \mathrm{~mm}$ higher than GlobVapour when TCWV $<15 \mathrm{~mm}$ and about $1 \mathrm{~mm}$ lower when TCWV $>15 \mathrm{~mm}$.
\end{abstract}

\section{Introduction}

Water vapor is an important factor for the weather and climate. It is the most abundant greenhouse gas and can amplify the effect of other greenhouse gases through positive feedback. It can condense to form clouds that greatly influence the heating rate and circulation of the atmosphere. In addition, it can influence atmospheric composition through photochemical reactions. Water vapor is highly variable in space and time. Better knowledge of its distribution is highly beneficial for predicting the weather, monitoring the climate, and understanding the physics and chemistry of the atmosphere.

Water vapor has been observed using a variety of in situ and remote-sensing techniques. Satellite remote sensing of water vapor has led to products retrieved from the visible (e.g., GOME, Wagner et al., 2003; Lang et al., 2007; SCIAMACHY, Noël et al., 2005; GOME-2, Grossi et al., 2015; Ozone Monitoring Instrument (OMI), Wang et al., 2014), near-infrared (e.g., SCIAMACHY, Schrijver et al., 2009; MODIS, Diedrich et al., 2015; MERIS, Lindstrot et al., 2012), infrared (e.g., MODIS, Seemann et al., 2003; AIRS, Bedka et al., 2010; IASI, Pougatchev et al., 2009), microwave (e.g., SSM/I, Schlüssel and Emery, 1990; Wentz, 1997), and GPS radio signals (e.g., Wang et al., 2007; Kishore et al., 2011). These data sets offer the unique opportunity to study water vapor distribution on a global scale. Among them, microwave and GPS measurements can be made under all sky conditions. Other types of measurements are strongly affected by clouds. Infrared measurements can provide vertical profiles but have low sensitivity to the planetary boundary layer where most water vapor resides. Microwave measurements are only available over non-precipitating ice-free ocean. Near-infrared measurements have better quality over land. Visible measure- 
ments are available for both land and ocean but are limited to nearly cloud-free daytime conditions.

Wang et al. (2014) derived total column water vapor (TCWV, also known as the total precipitable water) using the spectra measured by OMI. The Level 2 data for 2005-2009 generated using the Wang et al. (2014) algorithm (version 1.0) have been archived at the Aura Validation Data Center (AVDC, http://avdc.gsfc.nasa.gov/index.php? site $=1389025893 \& i d=87$ ). A detailed assessment of data quality is important for data usage in various weather and climate studies. In this paper, we perform a comprehensive validation of this product using the ground-based GPS data from National Center for Atmospheric Research (NCAR), the near-infrared sun-photometer data from Aerosol Robotic Network (AERONET), and the microwave radiometer data from Remote Sensing System (RSS). An updated OMI retrieval algorithm is also presented. The new results are compared against RSS's microwave radiometer data and GlobVapour's MERIS + SSM/I data. The data sets used in this study are introduced in Sect. 2. The validation of the version 1.0 OMI data is performed in Sect. 3. The algorithm update is presented in Sect. 4. A summary is provided in Sect. 5.

\section{Total column water vapor data}

\subsection{OMI data}

OMI is an ultraviolet/visible (UV/vis) imaging spectrometer on board the NASA EOS-Aura satellite. It has three spectral channels spanning the 264-504 nm spectral region at 0.4-0.6 nm spectral resolution (Levelt et al., 2006). OMI has been providing daily global observations at 13:45 LT with a nominal spatial resolution of $13 \mathrm{~km} \times 24 \mathrm{~km}$ at nadir since July 2004.

Water vapor exhibits several distinct spectral bands in the OMI visible channel (349-504 nm). These features are several orders of magnitude weaker than those at longer wavelengths. However, they can still be exploited to retrieve TCWV (Wagner et al., 2013; Wang et al., 2014). Since water vapor is a weak absorber in the blue spectral range, the retrieval is free from the complication of nonlinearity due to saturation. Since the surface albedo is more uniform over the globe in this spectral region, the signals do not change abruptly between land and ocean. Water vapor derived from the blue spectral range can greatly enhance the scientific return of satellites, especially for those with instruments that lack spectral coverage at longer wavelengths (e.g., OMI).

Wang et al. (2014) retrieved TCWV from OMI spectra using the $430-480 \mathrm{~nm}$ retrieval window. The retrieval method consists of two steps. First, the slant column density (SCD) is derived from a spectral fitting algorithm that considers water vapor, $\mathrm{O}_{3}, \mathrm{NO}_{2}, \mathrm{O}_{2}-\mathrm{O}_{2}$, liquid water, $\mathrm{C}_{2} \mathrm{H}_{2} \mathrm{O}_{2}$, the Ring effect, the water Ring effect, third-order closure polynomials, wavelength shift, under-sampling, and com- mon mode. The median SCD fitting uncertainty is about $11 \%$ (Wang et al., 2014). Then, the vertical column density (VCD) is obtained by dividing the SCD with an air mass factor (AMF) that is based on a radiative transfer calculation. Wang et al. (2014) found that the AMF was insensitive to wavelength but sensitive to surface albedo and highly sensitive to clouds. The albedo used in the AMF calculation is from an updated version of the OMLER climatology at $0.5^{\circ} \times 0.5^{\circ}$ spatial resolution (Kleipool et al., 2008). The cloud fraction and cloud top pressure used in the AMF calculation are from the second release of version 003 Level 2 OMCLDO2 product, which is derived from the $\mathrm{O}_{2}-\mathrm{O}_{2}$ absorption band near $477 \mathrm{~nm}$ (Acarreta et al., 2004; Stammes et al., 2008). The VCD in molecules $\mathrm{cm}^{-2}$ can be converted to TCWV in mm using a multiplicative factor of $2.989 \times 10^{-22}$. The collection 3 version 1.0 Level 2 OMI water vapor data from 2005 to 2009 have been released at the AVDC website (http://avdc.gsfc.nasa.gov/index. php? site $=1389025893 \& i d=87$ ). These data are validated in Sect. 3.

It should be noted that there are artificial stripes in the Level 2 OMI water vapor data. These stripes are due to systematic errors related to instrument calibration. They can be smoothed by post-processing Level 2 data. One smoothing method is to divide each line of SCD with a onedimensional (1-D) smoothing array (Wang et al., 2014). As an example, the smoothing array as a function of cross-track pixel number is shown for July 2005 (black) and July 2009 (gray) in Fig. 1. It is calculated from the monthly average of Level 2 SCDs and normalized using a third-order polynomial fit (as a function of cross-track pixel number). The SCDs used are filtered to pass the main data quality check $(\mathrm{MDQFL}=0)$, have root mean squared (RMS) fitting error $<5 \times 10^{-3}$ and cloud fraction $<0.05$. The MDQFL criterion checks that the fitting has converged, the retrieved SCD is $<4 \times 10^{23}$ molecules $\mathrm{cm}^{-2}$ and the SCD is positive within $2 \sigma$ fitting uncertainty. Figure 1 shows a large pixel-to-pixel variation of up to $17 \%$. Consequently, the stripes in OMI Level 2 data can significantly influence comparisons with other data sets on a daily timescale. OMI began to experience row anomalies since June 2007 (http://projects.knmi. nl/omi/research/product/rowanomaly-background.php). The affected rows in July 2009 are highlighted by dots in Fig. 1. They appear to be more oscillatory than those in July 2005. However, the standard deviation of the smoothing array only increases from $6 \%$ for July 2005 to $7 \%$ for July 2009. While the data affected by OMI row anomaly should be used with caution, their variation does not seem to be much larger than before, at least until July 2009.

Another smoothing method is to subtract a 1-D offset array (as a function of pixel number) from the SCD before its conversion to VCD. The offset array can be derived from a reference region, such as the Sahara. The mean SCD of each cross-track pixel in the reference region is calculated using the swaths obtained within a week, a low-order (e.g., third- 


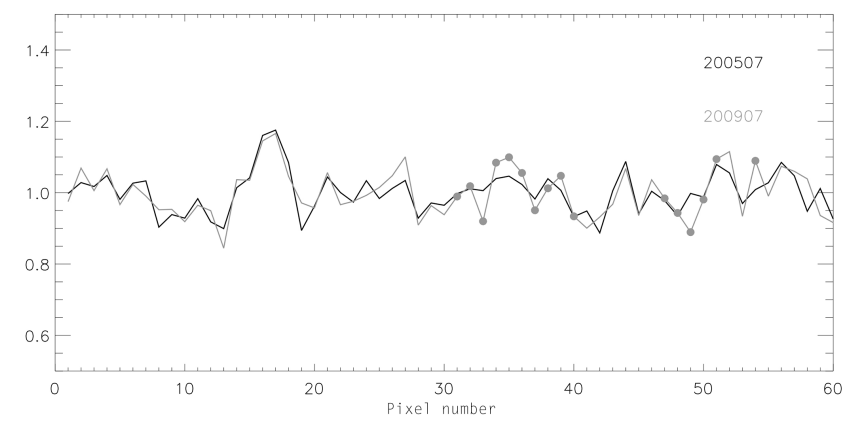

Figure 1. Smoothing array for stripes in version 1.0 OMI TCWV as a function of cross-track pixel number for July 2005 (black) and July 2009 (gray). The pixels affected by the row anomaly are indicated by dots.

order) polynomial is subsequently removed, and the resulting 1-D array is used as the offset array. Since the smoothing procedure is non-unique and can potentially introduce an additional bias, we use the un-smoothed Level 2 OMI data (with stripes) in this paper.

\subsection{NCAR's ground-based GPS data}

NCAR hosts a 2-hourly TCWV data set derived from the ground-based GPS measurements of zenith path delay at stations in the International GNSS Service (IGS), SuomiNet, and GEONET networks (Wang et al., 2007). We have downloaded the data from http://rda.ucar.edu/datasets/ds 721 . 1/ (EOL/NCAR/UCAR, 2011, updated yearly). The IGSSuomiNet data include 1160 stations worldwide and are available from 1995 to 2012. The ground-based GPS data have been extensively used to validate other TCWV measurements and data assimilation products (Wang and Zhang, 2008; Sibylle et al., 2010; Mears et al., 2015). The GPS TCWV retrieval error is estimated to be $1.5 \mathrm{~mm}$ (Wang et al., 2007). The mean difference between the GPS and satellite microwave radiometer data over the ocean is $<1 \mathrm{~mm}$ and the standard deviation is $<2 \mathrm{~mm}$ (Mears et al., 2015). In this paper, we use the subset of IGS-SuomiNet data from 2005 to 2009 to compare with the OMI data.

\subsection{AERONET's sun-photometer data}

AERONET provides globally distributed observations of aerosol optical depth, TCWV, and other variables using sunphotometers (Holben et al., 1998). The network has expanded from 16 sites in 1993 to 860 sites in 2014. TCWV is derived from the $940 \mathrm{~nm}$ filter that coincides with the $2 v_{1}+v_{2}$ water vapor absorption band. The Level 2.0 AERONET data are cloud screened and quality assured (Smirnov et al., 2000). We have downloaded the publicly available version 2 Level 2.0 data from http://aeronet.gsfc.nasa.gov/new_web/ data.html and used the subset from 2005 to 2009 to compare with the OMI data. Using the subset of AERONET data observed at the sites operated by the US Department of Energy Atmospheric Radiation Measurement (ARM) program, Pérez-Ramírez et al. (2014) found that the AERONET TCWV had a general dry bias of 5-6\% and an estimated uncertainty of $12-15 \%$. The version 3 AERONET data are currently under development and is expected to be released in 2016 .

\subsection{RSS's microwave data}

RSS generates TCWV data by processing the microwave data from Special Sensor Microwave/Imager (SSM/I), Special Sensor Microwave Imager Sounder (SSMIS), and other sensors. The retrieval uses a unified physically based algorithm which yields a retrieval accuracy of $1.2 \mathrm{~mm}$ (Wentz, 1997). The TCWV data derived from these satellite microwave radiometers are available under all sky nonprecipitating conditions over the ice-free ocean. They have long been considered as among the most reliable and have been routinely assimilated into numerical models. We have downloaded from http://www.remss.com/support/ data-shortcut the latest version 7 SSMIS data collected by the Defense Meteorological Satellite Program's (DMSP) F16 satellite (Wentz et al., 2012). These data are obtained in both the morning (04:06 LT) and the evening (16:06 LT), while OMI data are obtained in the early afternoon (13:45 LT). The diurnal cycle of TCWV varies with season and region and can sometimes exceed $2 \mathrm{~mm}$ (Wang et al., 2007). Abnormal conditions (heavy rain, sea ice, bad data, no observation, and land) are flagged in the SSMIS data. In this paper, we make use of the daily gridded $\left(0.25^{\circ} \times 0.25^{\circ}\right) \mathrm{SSMIS}$ product from 2005 to 2009.

\subsection{GlobVapour's MERIS + SSM/I data}

The GlobVapour project sponsored by the European Space Agency (ESA) Data User Element (DUE) program generated a global Level $3\left(0.5^{\circ} \times 0.5^{\circ}\right) \mathrm{TCWV}$ product by combining MERIS land and SSM/I ocean observations from 2003 to 2008 (http://www.globvapour.info). The MERIS nearinfrared data are collected around 10:00 LT and derived from the water vapor absorption around $950 \mathrm{~nm}$. The SSM/I microwave data are collected around 06:00 LT and derived using a 1D-Var method for ice-free non-precipitating ocean. The GlobVapour Level 3 product combines clear sky MERIS land data with all sky SSM/I ocean data. Over the land, GlobVapour is on average about $-1.3 \mathrm{~mm}$ lower than the GCOS Upper-Air Network (GUAN) radiosonde data and $+0.2 \mathrm{~mm}$ higher than the AIRS clear sky infrared data. Over the ocean, it is on average about $+1.3 \mathrm{~mm}$ higher than GUAN and $+0.7 \mathrm{~mm}$ higher than AIRS. The standard deviation of the difference ranges from 2 to $5 \mathrm{~mm}$ (Bojkov, 2012). Wang et al. (2014) compared the monthly mean GlobVapour data with the monthly mean version $1.0 \mathrm{OMI}$ data. They found an overall agreement (within $1 \mathrm{~mm}$ ) over land and an OMI low bias 

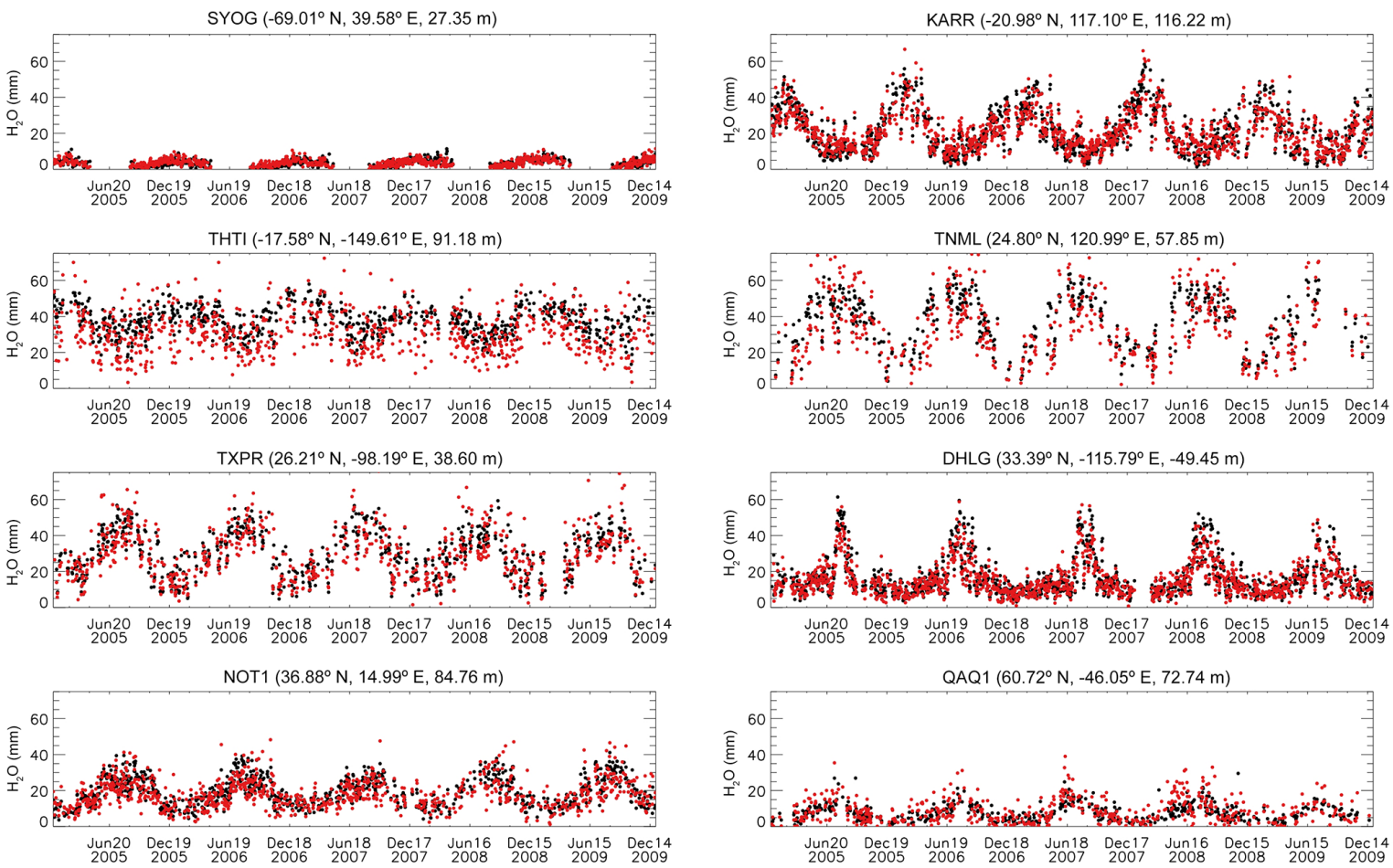

Figure 2. Time series comparison between the version 1.0 OMI (red) and GPS (black) data at selected GPS stations from 1 January 2005 to 31 December 2009

of $-3 \mathrm{~mm}$ or more over the ocean. In this paper, we sample the daily gridded GlobVapour data to compare with the updated OMI data in Sect. 4.

\section{V1.0 OMI TCWV validation}

\subsection{OMI and GPS}

The AVDC collection 3 Level 2 OMI TCWV data processed with Smithsonian Astrophysical Observatory's (SAO) version 1.0 algorithm are filtered and co-located with NCAR's ground-based GPS data. The filtering criteria for OMI require that the general quality check is passed (MDQFL $=0)$. The cross-track quality flag indicates that the retrieval is not affected by OMI's row anomaly. The SCD fitting RMS is $<5 \times 10^{-3}$, the cloud fraction is $<10 \%$, the cloud top pressure is $>500 \mathrm{hPa}$, and the AMF is $>0.75$. Since clouds can dramatically change the vertical sensitivities and lead to large errors in OMI VCDs (Wang et al., 2014), the last three filtering criteria are intended to mitigate their influence. These filtering criteria are also used in subsequent sections unless otherwise specified. Most of the OMI data are filtered out due to cloud contamination. For 1 July 2005, there are about 1255000 data points satisfying the partial criteria of $\mathrm{MDQFL}=0$, no row anomaly, and RMS $<5 \times 10^{-3}$. Their average TCWV is $29.2 \mathrm{~mm}$. Only about $30 \%$ of these data pass the full filtering criteria, and their average is $21.7 \mathrm{~mm}$.
This suggests that clouds tend to increase the amount of retrieved TCWV in OMI data.

For co-location at each GPS station, we select the GPS observations made between the local noon and 14:00 LT each day. For each eligible GPS data point, we search the filtered OMI data on the same day for the pixels that are within $0.25^{\circ}$ latitude $\times 0.25^{\circ}$ longitude of the GPS station. For July 2005, co-located OMI data can be found for about half of the GPS observations. Among them, there are typically around four (within a range of 1-16) OMI data points for each GPS data point. When multiple OMI data points are available for a single GPS data point, the average weighted by the OMI SCD fitting error is calculated and used for comparison.

Figure 2 shows the TCWV time series comparison between the GPS and OMI data at selected sites. These sites are scattered around the world (denoted by "X" in Fig. 3) and represent a variety of climate regimes. For both dry and wet conditions and for both small and large seasonal cycles, the OMI data track the seasonal and interannual variations of the GPS data well, even with the influence of stripes. This demonstrates the value of TCWV retrieved from OMI.

The top panel of Fig. 3 shows the OMI-GPS TCWV difference averaged within the time period from 1 January 2005 to 31 December 2009 for the IGS-SuomiNet stations. For this plot, we have excluded the stations with significant topography difference (i.e., those with elevations that are different than the local gridded $\left(0.25^{\circ} \times 0.25^{\circ}\right)$ topography by $500 \mathrm{~m}$ 

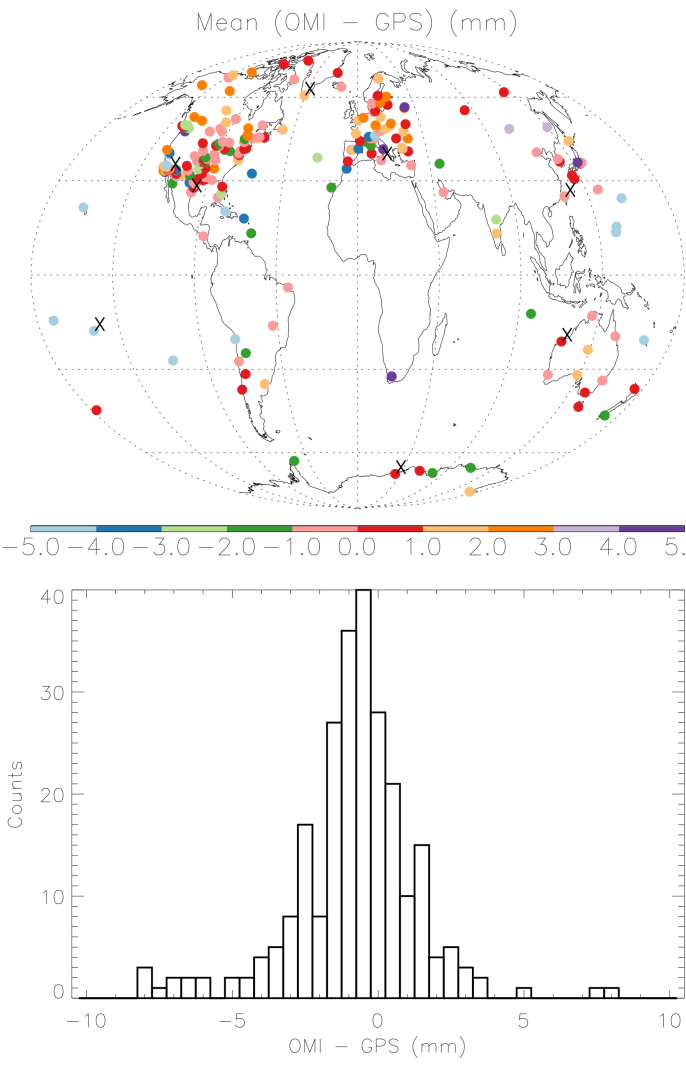

Figure 3. Top: spatial distribution of the mean of version 1.0 OMI-GPS from 2005 to 2009 at IGS-SuomiNet stations. Bottom: histogram (with $0.5 \mathrm{~mm}$ bins) for the values in the top panel.

or more). We have also excluded the stations with $<100$ data points. There are 250 stations in Fig. 3. Many are in North America and Europe, but very few are in Africa and on ocean islands. Generally speaking, OMI data agree well with GPS data over land but are significantly lower over the ocean. The histogram for the mean OMI-GPS TCWV difference (shown in the top panel) is plotted in the bottom panel of Fig. 3. It is binned by $0.5 \mathrm{~mm}$ and has a mode of $-0.5 \mathrm{~mm}$. OMI data agree with GPS data within $1.5 \mathrm{~mm}$ at $71 \%$ of the stations and within $3 \mathrm{~mm}$ at $89 \%$ of the stations. OMI data are higher than GPS data by $3 \mathrm{~mm}$ or more at eight stations, where all except for one station are located in coastal areas. OMI data are lower than GPS data by $3 \mathrm{~mm}$ or more at 23 stations, where all except for 2 stations are located on ocean islands or in coastal areas. OMI data are lower than GPS data by $5 \mathrm{~mm}$ or more at 10 stations, among which 2 stations are located in coastal areas and the others are on ocean islands.

In the top row of Fig. 4, we compare OMI with GPS TCWV using all available data pairs at all land (left) and ocean (right) stations from 2005 to 2009. Since most GPS stations are over land, the number of data points over land (317 118) far exceeds that over the ocean (2621). The data in the 2-D histogram of OMI vs. GPS are binned every $0.5 \mathrm{~mm}$
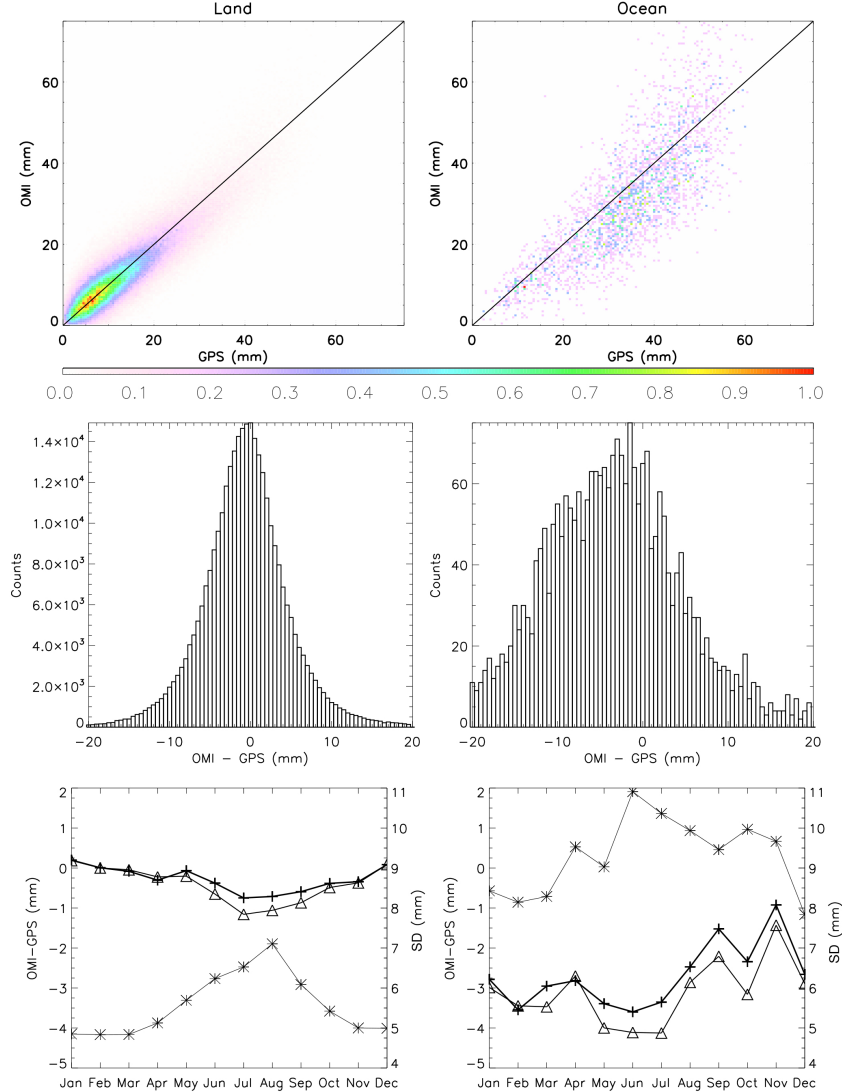

Figure 4. Top: 2-D normalized histograms for (left) land and (ocean) derived from all the paired version 1.0 OMI and GPS data at all suitable IGS-SuomiNet stations from 1 January 2005 to 31 December 2009. Results are shown for $0.5 \mathrm{~mm} \times 0.5 \mathrm{~mm}$ bins, with the largest binned value normalized to 1 . The black line in each panel corresponds to $1: 1$. Middle: histograms of OMI-GPS derived from the same data as those used in the top panel. The counts correspond to $0.5 \mathrm{~mm}$ bins. Bottom: median (triangle, left axis), mean (cross, right axis), and standard deviation (star, right axis) of version 1.0 OMI-GPS as functions of month.

of TCWV. The largest color-coded value in each panel is normalized to one. The GPS TCWV data over land are mostly within the range of $4 \mathrm{~mm}$ (10\% percentile) to $34 \mathrm{~mm}(90 \%$ percentile) and those over the ocean are mostly within the range of 17 to $50 \mathrm{~mm}$. The OMI data generally follow the GPS data along the $1: 1$ line over land but tend to be lower than the GPS data (i.e., below the $1: 1$ line) over the ocean.

The middle row of Fig. 4 shows the histograms for the OMI-GPS differences using the data shown in the top row. The histogram for land stations has a peak at $0 \mathrm{~mm}$. The distribution is slightly asymmetric, with a full width at half maximum (FWHM) of $8.5 \mathrm{~mm}$ (from -5.0 to $3.5 \mathrm{~mm}$ ). The mean and median of the distribution are -0.3 and $-0.4 \mathrm{~mm}$, respectively. The scatter is related to random errors in GPS data and random errors in OMI SCD, AMF, and stripes. The histogram for the ocean stations is much less smooth due to the 

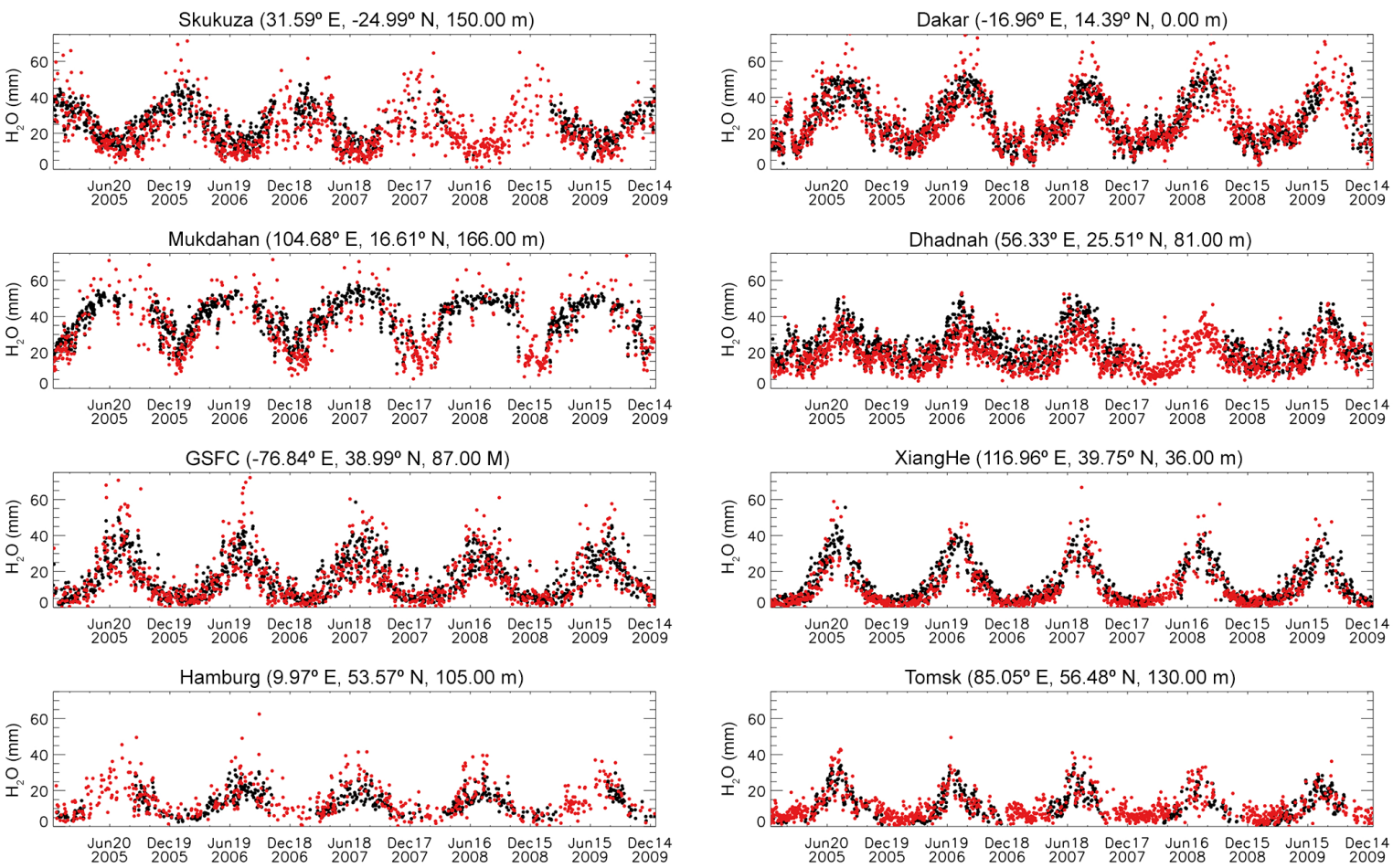

Figure 5. Time series comparison between version 1.0 OMI (red) and AERONET (black) at selected AERONET stations from 1 January 2005 to 31 December 2009.

smaller sample size. The distribution is apparently skewed towards more negative values and has a larger scatter. The mode, mean, and median of OMI-GPS over the ocean are $-1.5,-3$, and $-3.5 \mathrm{~mm}$, respectively.

The bottom row of Fig. 4 shows the mean (cross, left axis), median (triangle, left axis), and standard deviation (star, right axis) of OMI-GPS as functions of month for all the land (left) and ocean (right) GPS stations. They are calculated using all the paired land (left) or ocean (right) data for the corresponding month from 2005 to 2009 . The number of data points used for each month is about 20000-30000 for the land stations and only about $190-240$ for the ocean stations. For land stations, the median of OMI-GPS is close to $0 \mathrm{~mm}$ from December to May, and becomes the most negative (around $-1 \mathrm{~mm}$ ) in July. The mean of OMI-GPS follows a similar trend. The standard deviations vary between 4.8 and $7.1 \mathrm{~mm}$, with a maximum in August. For ocean stations, the sample size is much smaller. Nevertheless, results show larger low biases for OMI. The means of OMI-GPS vary between -1 and $-4 \mathrm{~mm}$, and the standard deviations vary between 8 and $11 \mathrm{~mm}$. The largest differences occur in June/July, as do the standard deviations.

\subsection{OMI and AERONET}

We filter and co-locate OMI and AERONET TCWV data using the same procedure as that in Sect. 3.1. Figure 5 shows time series comparisons at selected AERONET sites. These sites represent a wide range of water vapor amounts and seasonal cycles around the world (denoted by " $X$ " in Fig. 6). In general, OMI observations track the variations of AERONET data well throughout 2005-2009. During the wet season, OMI data appear to be higher at several sites (e.g., Skukuza, Mukdahan, GSFC, Hamburg, and Dakar).

In Fig. 6, we examine the spatial distribution and histogram of the mean of OMI-AERONET for the time period from 2005 to 2009. As in Fig. 3, we have omitted the sites with substantial topography difference and the sites with $<100$ data points. Of the 160 stations shown in Fig. 6, there are only about 10 over the ocean. Figure 6 shows that OMI is generally higher over land and lower over the ocean and in some coastal areas. The histogram shows a main peak at $0.5 \mathrm{~mm}$ and a secondary peak at $-2.5 \mathrm{~mm}$. The secondary peak is due to the ocean sites. $59 \%$ of the sites show a non-negative OMI-AERONET difference. Pérez-Ramírez et al. (2014) found a dry bias of AERONET TCWV at the US Southern Great Plains, Barrow Island (in Alaska), and Nauru Island (in the tropical western Pacific). Figure 6 suggests that OMI is slightly wetter than AERONET in the contiguous USA and Alaska but is even drier than AERONET at Nauru island.

In Fig. 7, we compare OMI with AERONET TCWV using all data pairs from 2005 to 2009 at all land (left) and ocean (right) sites. The top row shows the 2-D normalized histograms for OMI vs. AERONET data and the middle row 

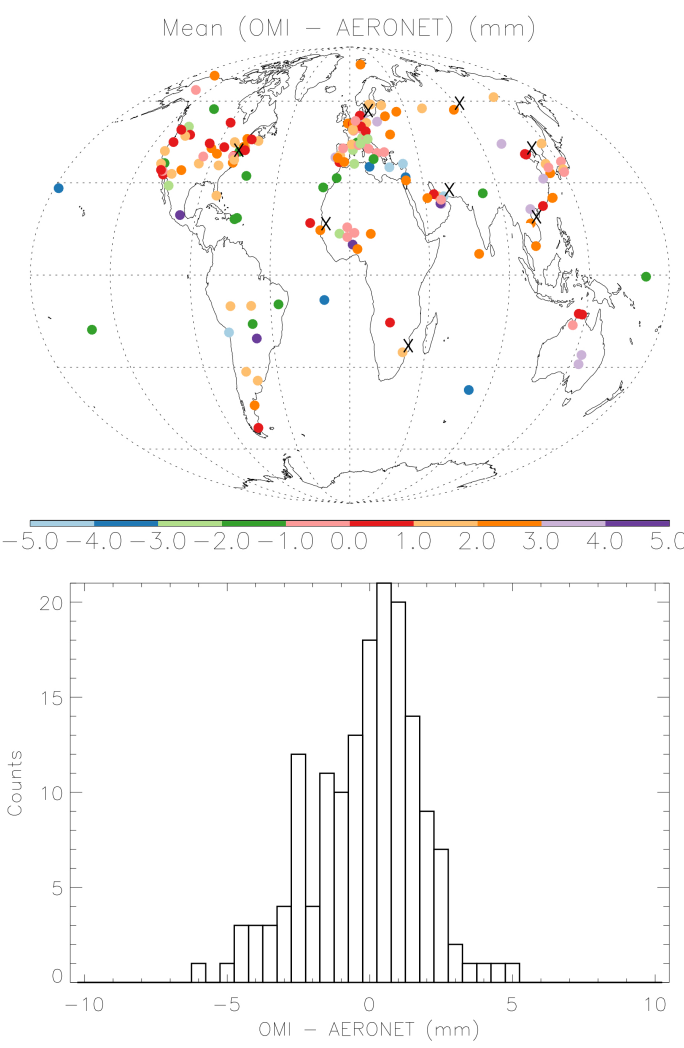

Figure 6. Top: spatial distribution of the time mean of version 1.0 OMI-AERONET from 2005 to 2009 at AERONET stations. Bottom: histogram (with $0.5 \mathrm{~mm}$ bins) for the values in the top panel.

shows the histograms for OMI-AERONET. Both are calculated using $0.5 \mathrm{~mm}$ bins. There are far more data points over land (91350) than over the ocean (3092). TCWV over the ocean is generally larger than that over land. The 10 and $90 \%$ percentiles of AERONET data for the ocean sites are 13 and $45 \mathrm{~mm}$, while those for the land sites are 6 and $32 \mathrm{~mm}$. Figure 7 shows that OMI generally agrees with AERONET well over land, but tends to be lower than AERONET over the ocean. The mean (median) of OMI-AERONET is $0 \mathrm{~mm}$ $(-0.3 \mathrm{~mm})$ for land and $-2.0 \mathrm{~mm}(-2.6 \mathrm{~mm})$ for the ocean. The OMI-AERONET histogram for land has a peak at $-1 \mathrm{~mm}$ and an FWHM of $8.5 \mathrm{~mm}$ (from -5.0 to $3.5 \mathrm{~mm}$ ), while that for the ocean has a peak at $-3.5 \mathrm{~mm}$ and an FWHM of $12 \mathrm{~mm}$ (from -9.5 to $2.5 \mathrm{~mm}$ ). The means, medians, and standard deviations of OMI-AERONET as functions of month are shown in the bottom row for land (left) and ocean (right) sites. The mean of OMI agrees with that of AERONET within $0.3 \mathrm{~mm}$ over land, but is lower than AERONET by 0.6 to $2.4 \mathrm{~mm}$ over the ocean. These differences are a little smaller than those shown in Fig. 4, which is consistent with a dry bias of AERONET TCWV reported by Pérez-Ramírez et al. (2014). The standard deviations of OMI-AERONET vary between 7 and $10 \mathrm{~mm}$ which are similar to those of OMI-GPS.
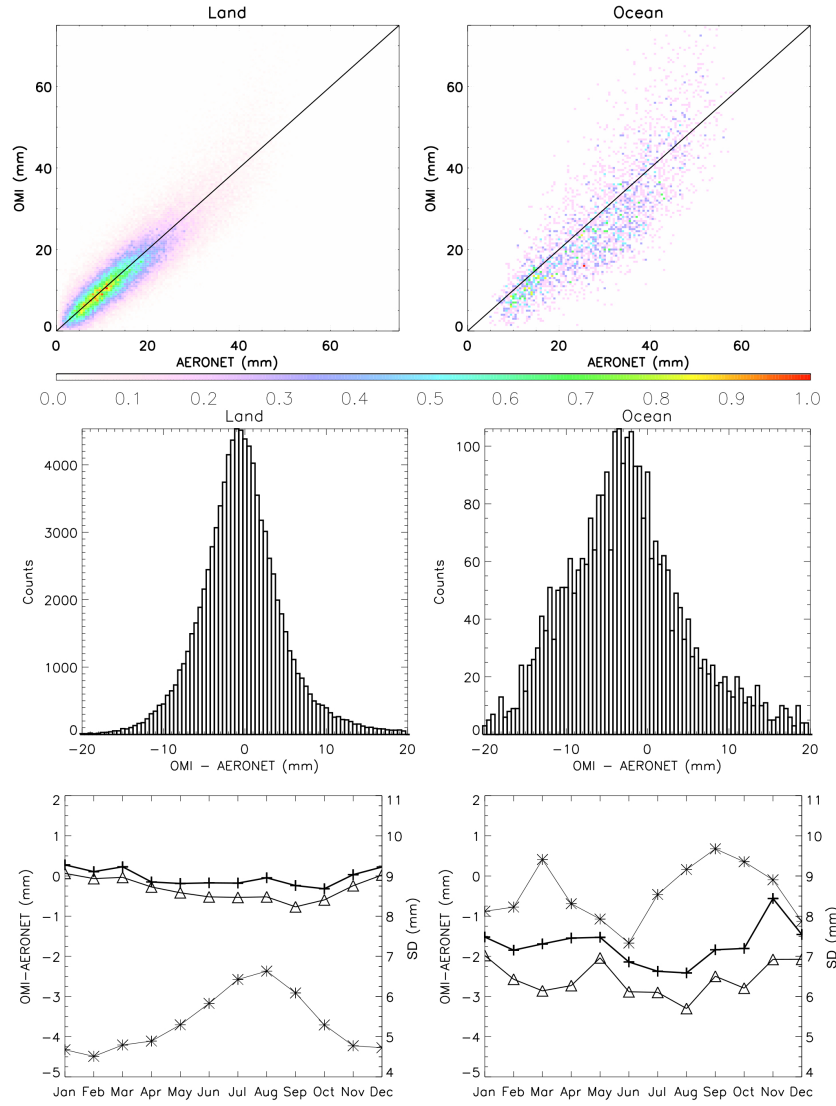

Figure 7. Top: 2-D normalized histograms for (left) land and (right) ocean derived from all the paired version 1.0 OMI and AERONET data at all suitable AERONET stations from 1 January 2005 to 31 December 2009. Results are shown for $0.5 \mathrm{~mm} \times 0.5 \mathrm{~mm}$ bins, with the largest binned value normalized to 1 . The black line in each panel corresponds to $1: 1$. Middle: histograms of version 1.0 OMI-AERONET derived from the same data as those used in the top row. The counts correspond to $0.5 \mathrm{~mm}$ bins. Bottom: mean (triangle, left axis), media (cross, right axis), and standard deviation (star, right axis) of version 1.0 OMI-AERONET as functions of month for (left) land and (right) ocean sites.

\subsection{OMI and SSMIS}

The ground-based networks discussed before have poor coverage over the ocean, but the SSMIS TCWV data from RSS are specifically for the ocean and have long-term daily coverage. We will therefore use the SSMIS data as the reference for the ocean. In Fig. 8, we compare the monthly mean OMI data (top row) with the monthly mean SSMIS data (middle row) for July 2005 . The monthly gridded $\left(0.25^{\circ} \times 0.25^{\circ}\right)$ OMI and SSMIS data are calculated from the monthly average of coincident daily gridded $\left(0.25^{\circ} \times 0.25^{\circ}\right)$ Level 3 data.

The daily Level 3 SSMIS data are downloaded from RSS's website (http://www.remss.com). Both the morning and evening passes are used in the monthly average. Pixels with bad data and rain are filtered out. The resulting "all 


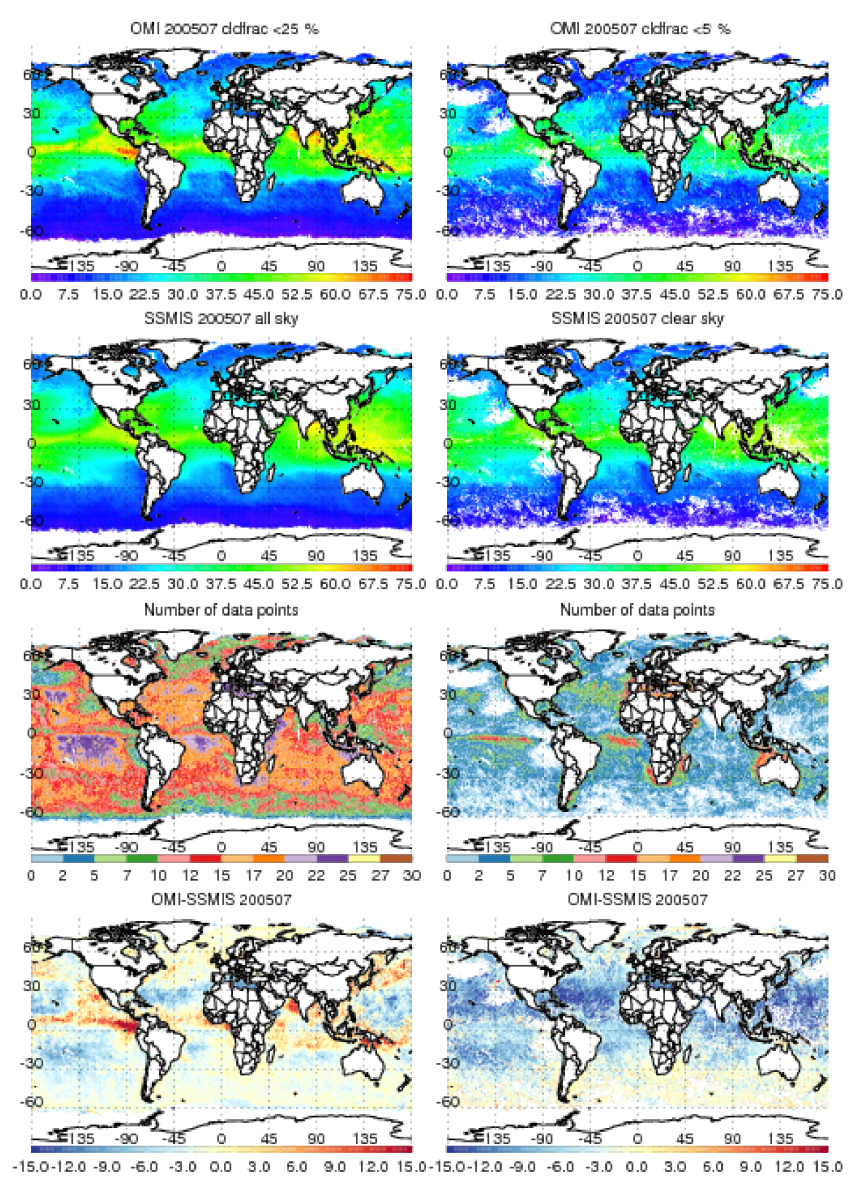

Figure 8. First row: monthly mean version 1.0 OMI TCWV (mm) for cloud fraction (left) $<25 \%$ and (right) $<5 \%$ for July 2005 . Second row: monthly mean SSMIS TCWV (mm) for July 2005 for (left) all sky and (right) "clear" sky conditions. Third row: number of coincident data points per pixel within July 2005 for the corresponding column. Fourth row: first row-second row. White areas in the maps represent missing data.

sky" data are associated with both clear sky and cloudy sky conditions. In addition to water vapor column and rain rate, RSS's data also provide "cloud liquid water path" for each pixel. In this paper, we use it to define a "clear" sky condition by ignoring the pixels whose cloud liquid water path is $>0$. Clouds in liquid phase are filtered out, but ice clouds still remain. However, information for cloud ice is unavailable in the RSS data used in this study. Therefore, the "clear" sky conditions referred to in this paper should be considered as an approximation to cloud-free conditions.

The daily Level 3 OMI data are derived from the corresponding Level 2 data using the average weighted by pixel area and slant column fitting uncertainty (Wang et al., 2014). The selection criteria for gridding the OMI Level 2 data include $\mathrm{MDQF}=0$, no row anomaly, RMS $<5 \times 10^{-3}$, $\mathrm{AMF}>0.75$, cloud top pressure $>500 \mathrm{mb}$, and cloud fraction $<$ a cutoff value.
To compare with the "clear" sky monthly SSMIS data (second panel on the right of Fig. 8), the OMI Level 2 data are gridded with a cloud fraction cutoff of $5 \%$ (first panel on the right). Although a $0 \%$ cutoff is equivalent to the clear sky condition, we use a $5 \%$ cutoff here to retain more data for gridding. The number of days when both OMI and SSMIS data are available at each pixel is generally $<5$ (third panel on the right). Nevertheless, it can be seen that OMI captures the general spatial distribution of TCWV observed by SSMIS. However, OMI data tend to be lower over the tropical oceans. The OMI-SSMIS difference has a global median of $-4.7 \mathrm{~mm}$ and can be $<-10 \mathrm{~mm}$ in the western Pacific and Atlantic. The difference between OMI and "clear" sky SSMIS is smaller when a $10 \%$ cloud fraction cutoff is used (not shown), in which case the global median of OMI-"clear" sky SSMIS becomes $-3.0 \mathrm{~mm}$. However, the OMI data quality is generally lower for cloudier scene as the AMF is highly sensitive to cloud (Wang et al., 2014).

In the left column of Fig. 8, we compare the monthly mean OMI and SSMIS data under all sky conditions for July 2005. The monthly mean OMI data in the top left panel are calculated from the daily gridded OMI data using a relaxed cloud fraction cutoff of $25 \%$. This choice is based on a balance between the cloudiness and the data quality for OMI. The monthly mean SSMIS data in the second panel are calculated from the daily gridded all sky SSMIS data. Both data sets are sampled and averaged in the same way. The number of data points used for monthly averaging at each pixel (third panel) increases to $>15$ in most areas. Both the SSMIS (second row) and the OMI (first row) data show increases in TCWV as cloud amount increases (from the right to the left), but the increase is more pronounced in the OMI data. The OMI-SSMIS difference (bottom row) is smaller for the all sky comparison than for the "clear" sky comparison. Specifically, for the all sky case, the median difference becomes $-1.7 \mathrm{~mm}$, and the difference becomes less negative in the western Pacific and Atlantic. There are some positive values in the lower left panel. They are mostly located in areas of missing data in the lower right panel, suggesting that the positive values are associated with significant cloud cover (5$25 \%$ ). This further indicates that the version 1.0 OMI data tend to have a high bias under cloudy sky conditions and a low bias under clear sky conditions. The cloudy sky high bias is mainly due to the small AMF estimate, especially for clouds at high altitudes (not shown).

Figure 9 shows the same comparison as Fig. 8, but for January 2005. Both OMI and SSMIS data show the southward migration of the Intertropical Convergence Zone (ITCZ) from July to January and an increase of TCWV with cloud fraction (from the right to the left in the top two rows). Again, the increase is more pronounced for OMI than for SSMIS. For the "clear" sky comparison (right column), OMI has a large low bias over the southern ocean, which can be $-10 \mathrm{~mm}$ or more. The bias becomes less negative and even positive for the all sky conditions, indicating that TCWV for 


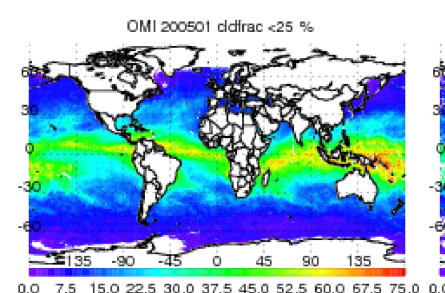

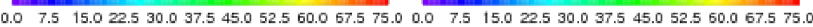
SSMIS 200501 all sky

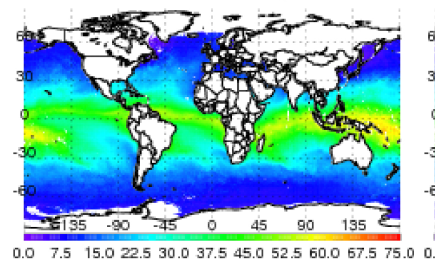

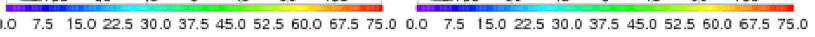
Number of data points
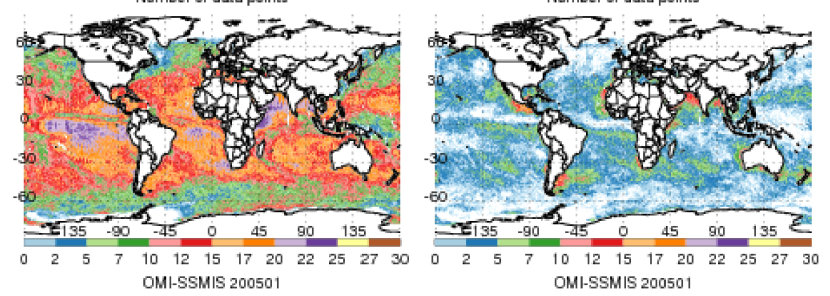

OMI-SSMIS 20050
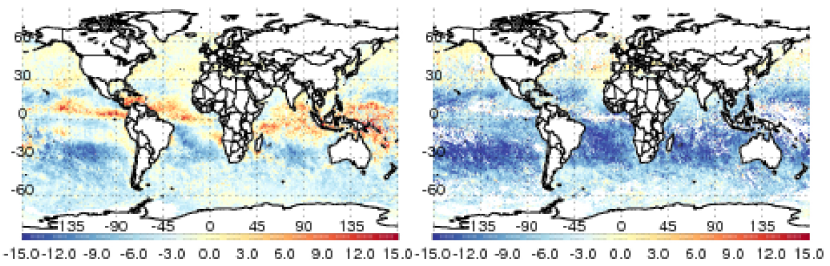

Figure 9. The same as Fig. 8 but for January 2005.

the pixels affected by clouds is higher for OMI than for SSMIS. The global median of OMI-SSMIS in January 2005 is $-6.5 \mathrm{~mm}$ for the "clear" sky comparison and $-2.9 \mathrm{~mm}$ for the all sky comparison.

The top row of Fig. 10 shows the 2-D normalized histograms of version 1.0 OMI vs. SSMIS for July 2005 (panels a, b) and January 2005 (panels c, d). The histograms are calculated using the daily gridded $\left(0.25^{\circ} \times 0.25^{\circ}\right)$ coincident data. The same OMI data filtering criteria as before are applied except for a cloud fraction cutoff of $10 \%$. This cutoff value is between the 5 and $25 \%$ used in Figs. 8 and 9 . We compare the OMI data with the "clear" sky SSMIS data in panels a and $\mathrm{c}$ and with the all sky SSMIS data in panels $b$ and d. For each month, about 1 million data points are used in the "clear" sky comparison and about 4 million in the all sky comparison. Both the "clear" sky and the all sky results show that OMI is generally lower than SSMIS. The OMI- "clear" sky SSMIS difference has a mean of $-3.7 \mathrm{~mm}$, a median of $-3.7 \mathrm{~mm}$, and a standard deviation of $7.2 \mathrm{~mm}$ in July 2005. The difference is larger in January 2005, with a mean of $-4.9 \mathrm{~mm}$, a median of $-4.9 \mathrm{~mm}$, and a standard deviation of $7.1 \mathrm{~mm}$. With the $10 \%$ cloud fraction cutoff, the version 1.0 OMI data are closer to the "clear" sky than to the all sky SSMIS data, as the OMI-all sky SSM/I difference has a mean of $-4.4 \mathrm{~mm}(-6.0 \mathrm{~mm})$, a median of $-4.3 \mathrm{~mm}$ $(-6.0 \mathrm{~mm})$, and a standard deviation of $7.7 \mathrm{~mm}(8.0 \mathrm{~mm})$ in July (January) 2005.

\section{Algorithm update}

\subsection{SCD fitting update}

The previous section shows that the AVDC collection 3 version 1.0 OMI data generally agree well with the reference data over land but are lower over the ocean. This implies a bias in the OMI SCD retrieval over the ocean. Wang et al. (2014) showed that liquid water is an important molecule to consider in their retrieval algorithm. They found that the fitting residual is generally larger over the ocean than over land. Moreover, the common mode derived over land appears largely random, but that derived over the ocean has apparent spectral structures, especially between 440 and $470 \mathrm{~nm}$ where the liquid water (Pope and Fry, 1997) and water Ring reference spectrum exhibit distinct spectral features. Consequently, errors in liquid water spectroscopy can lead to systematic errors in the water vapor retrieved over the ocean. Furthermore, the $430-480 \mathrm{~nm}$ retrieval window used by Wang et al. (2014) contains both the $7 v(435-450 \mathrm{~nm})$ and the $6 v+\delta(460-480 \mathrm{~nm})$ spectral bands of water vapor. Lampel et al. (2015) derived scaling factors for the water vapor absorption bands in the blue spectral range using the $7 v$ band as a reference. They suggested that the absorption strength of the $6 v+\delta$ band should be scaled by a factor of $1.02 \pm 0.07$ in HITRAN 2008 (Rothman et al., 2009). This would also affect the water vapor result derived from the $430-480 \mathrm{~nm}$ retrieval window.

To reduce the influence of errors in liquid water and water vapor cross sections, we have experimented with narrower retrieval windows. With a narrower retrieval window, scaling of the HITRAN water vapor spectrum can be avoided. Additionally, some broadband spectroscopy error of liquid water can be accounted for by the third-order closure polynomial. Using OMI orbit 5109, which cuts across the western Pacific on 1 July 2005, we varied the retrieval window around the $7 v$ water vapor band near $442 \mathrm{~nm}$ to maximize the retrieved median column amount and minimize the median SCD fitting uncertainty. In addition, since water vapor over the ocean is concentrated at the sea level, we have changed the water vapor reference spectra from one that corresponds to $0.9 \mathrm{~atm}$ and $280 \mathrm{~K}$ to one that corresponds to $1.0 \mathrm{~atm}$ and $288 \mathrm{~K}$. We recently obtained the $\mathrm{O}_{2}-\mathrm{O}_{2}$ reference spectra measured by Thalman and Volkamer (2013). We therefore updated it as well. All the other retrieval setups remain the same as those used in version 1.0 (Wang et al., 2014).

The optimized new retrieval window is between 427.7 and $465.0 \mathrm{~nm}$, from which we obtain a median VCD of $1.07 \times 10^{23}$ molecules $\mathrm{cm}^{-2}$ and a median fitting uncertainty 

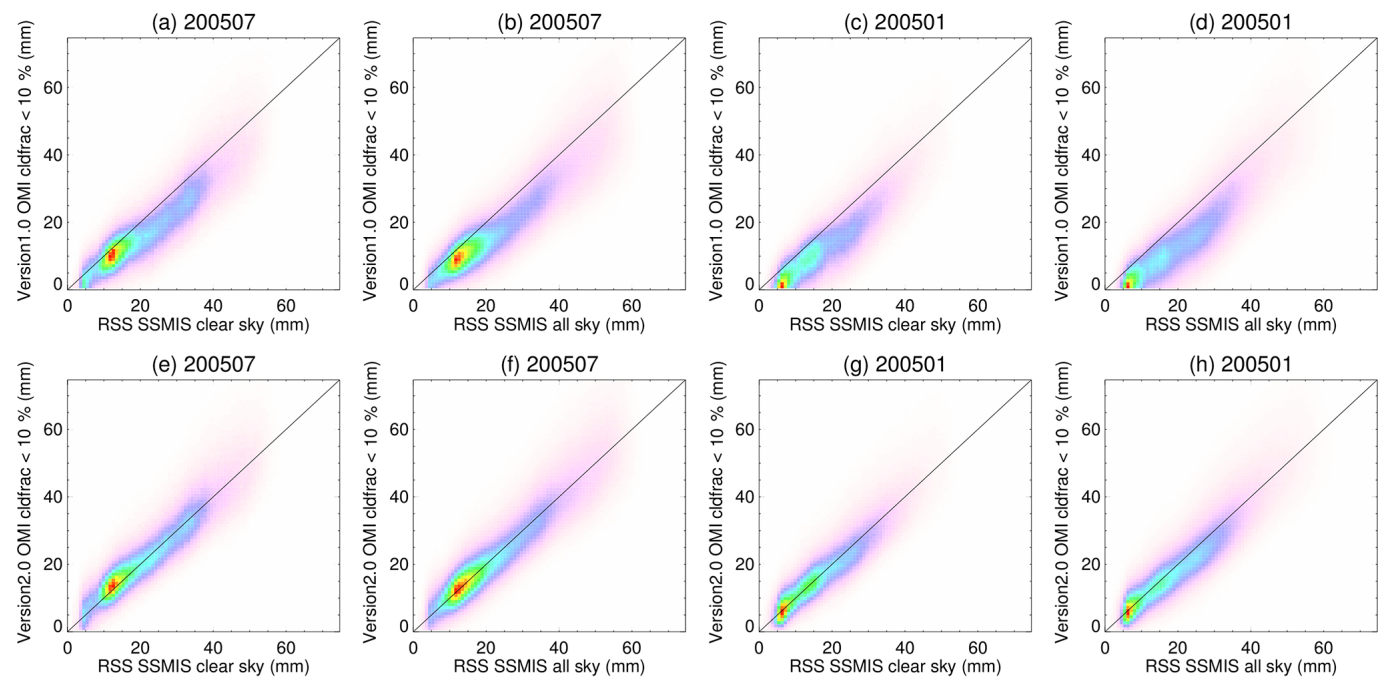

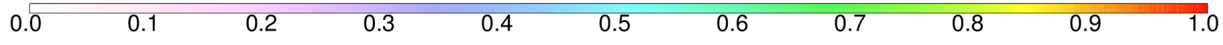

Figure 10. Two-dimensional normalized histograms derived from daily gridded $\left(0.5^{\circ} \times 0.5^{\circ}\right)$ OMI (with cloud fraction $\left.<10 \%\right)$ and SSMIS data using $0.5 \mathrm{~mm} \times 0.5 \mathrm{~mm}$ bins. The black line in each panel is the $1: 1$ line. (a) Version 1.0 OMI vs. "clear" sky SSMIS for July 2005; (b) version 1.0 OMI vs. all sky SSMIS for July 2005; (c) version 1.0 OMI vs. "clear" sky SSMIS for January 2005; (d) version 1.0 OMI vs. all sky SSMIS for January 2005; (e) version 2.0 OMI vs. "clear" sky SSMIS for July 2005; (f) version 2.0 OMI vs. all sky SSMIS for July 2005; (g) version 2.0 OMI vs. “clear” sky SSMIS for January 2005; (h) version 2.0 OMI vs. all sky SSMIS for January 2005.

of $1.4 \times 10^{22}$ molecules $\mathrm{cm}^{-2}$ for orbit 5109 . We will refer to this retrieval algorithm as version 2.0. For comparison, the retrieval window of $430.0-460.0 \mathrm{~nm}$ leads to a median VCD of $1.01 \times 10^{23}$ molecules $\mathrm{cm}^{-2}$ and a median uncertainty of $1.6 \times 10^{22}$ molecules $\mathrm{cm}^{2}$. For the same orbit, the version 1.0 algorithm leads to a median VCD of $8.6 \times 10^{22}$ molecules $\mathrm{cm}^{-2}$ and a median uncertainty of $1.1 \times 10^{22}$ molecules $\mathrm{cm}^{-2}$. Although the absolute fitting uncertainty of the version 2.0 algorithm is about $30 \%$ larger than that of version 1.0, the median relative uncertainties of both algorithms are about $12 \%$.

The difference in TCWV between the version 2.0 algorithm and the version 1.0 algorithm mainly comes from the change in retrieval window. With only the retrieval window change, the median VCD of orbit 5109 increases from $8.6 \times 10^{22}$ to $1.06 \times 10^{23}$ molecules $\mathrm{cm}^{-2}$. With a further change of the water vapor reference spectrum from 0.9 to $1.0 \mathrm{~atm}$, the median VCD increases to $1.07 \times 10^{23}$ molecules $\mathrm{cm}^{-2}$. Updating the $\mathrm{O}_{2}-\mathrm{O}_{2}$ reference spectrum has a negligible effect on the retrieval.

Using the version 2.0 setup described above, we retrieved the Level 2 TCWV for July and January 2005. Using the same method as that used in the top row of Fig. 10, we generated daily gridded version 2.0 OMI data with a $10 \%$ cloud fraction cutoff and compared them with the SSMIS daily gridded data in terms of the 2-D histogram distributions in the bottom row of Fig. 10. The agreement between the version 2.0 OMI and SSMIS data is much better than that between the version 1.0 OMI and SSMIS data. The low bias of the version 1.0 OMI is eliminated. For July 2005, the version 2.0 OMI data follow the all sky SSMIS data along the $1: 1$ line well and are slightly higher than "clear" sky SSMIS data (by about $1 \mathrm{~mm}$ ). For January, the version 2.0 OMI data follow the SSMIS data well when TCWV are below $20 \mathrm{~mm}$ and are slightly lower than the all sky SSMIS data for larger TCWV amount (by about $1 \mathrm{~mm}$ ).

To investigate the spatial distribution of the changes between the version 1.0 and version 2.0 OMI data, we compare the monthly mean Level 3 gridded $\left(0.25^{\circ} \times 0.25^{\circ}\right)$ data for July 2005. The same filtering criteria as before have been applied. The top row of Fig. 11 shows the version 2.0 OMI-version 1.0 OMI difference maps for a $5 \%$ (right) and a $25 \%$ (left) cloud fraction cutoff. In both cases, the version 2.0 OMI data increase slightly over land but substantially over the ocean. Specifically, for the $5 \%$ cloud fraction cutoff, the version 2.0 OMI data increase over the version 1.0 OMI data at AVDC by an average of $1.2 \mathrm{~mm}$ over land and $4.8 \mathrm{~mm}$ over the ocean. For the $25 \%$ cutoff, the version 2.0 OMI data increase by an average of $1.3 \mathrm{~mm}$ over land and $3.7 \mathrm{~mm}$ over the ocean.

In the bottom row of Fig. 11, we compare the version 2.0 OMI data with the SSMIS data for July 2005 using the same method as that for Fig. 8. The bottom right panel shows the result of version 2.0 OMI with a $5 \%$ cloud fraction cutoff-"clear" sky SSMIS. Comparing with the bottom right panel of Fig. 8, we find a better agreement here. Firstly, the previously found large low bias $(<-10 \mathrm{~mm})$ of version 1.0 OMI over the Pacific, Atlantic, and Indian oceans is re- 

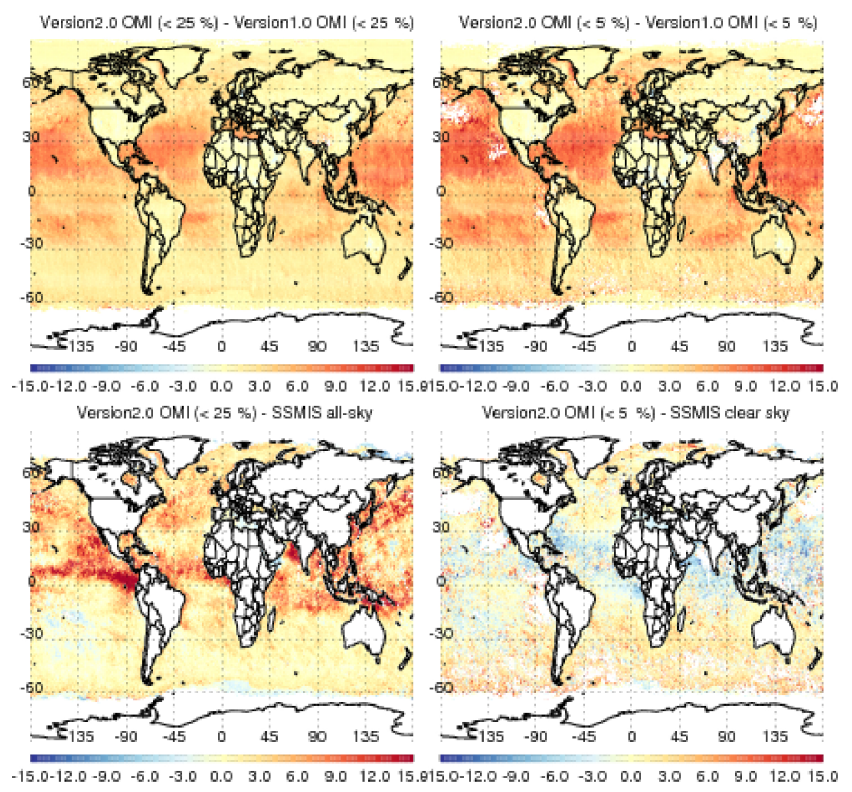

Figure 11. Top row: monthly mean of version 2.0 OMI-version 1.0 OMI for cloud fraction (left) $<25 \%$ and (right) $<5 \%$ for July 2005. Bottom left: monthly mean of version 2.0 OMI with cloud fraction $<25 \%$-all sky SSMIS for July 2005. Bottom right: monthly mean of version 2.0 OMI with cloud fraction $<5 \%$ - "clear" sky SSMIS for July 2005.

duced by more than half. Secondly, the global mean difference decreases to $0.1 \mathrm{~mm}$, which is much smaller than before $(-4.7 \mathrm{~mm})$. Although the southern and northern $\mathrm{mid} / \mathrm{high}$ latitudes show some moderate positive values, these areas are affected by the small number of coincident data points per pixel (third panel on the right of Fig. 8). The bottom left panel of Fig. 11 shows the difference of version 2.0 OMI with a $25 \%$ cutoff-all sky SSMIS. In comparison with the bottom left panel of Fig. 8, the version 2.0 OMI data generally do not show any large low bias. However, large high bias is seen in several places. As a result, the global mean over the ocean change from $-1.7 \mathrm{~mm}$ (Fig. 8) to $2.9 \mathrm{~mm}$ (Fig. 11). A comparison between the lower left and lower right panel of Fig. 11 reveals that these large positive values are consistently located in the vicinity of the missing data of the lower right panel, which indicates that they are affected by significant cloud cover. As discussed before, OMI cloudy data are expected to be less reliable and tend to overestimate TCWV. This will partly compensate for any low bias if the pixel is occasionally cloudy and show up as a high bias if the pixel is persistently cloudy.

\subsection{AMF update}

AMFs are used to convert SCDs to VCDs. Consequently, errors in AMFs also affect OMI TCWV. The AMFs in previous sections were derived by convolving the monthly mean water vapor profiles used in the GEOS-Chem model $\left(2^{\circ} \times 2.5^{\circ}\right)$

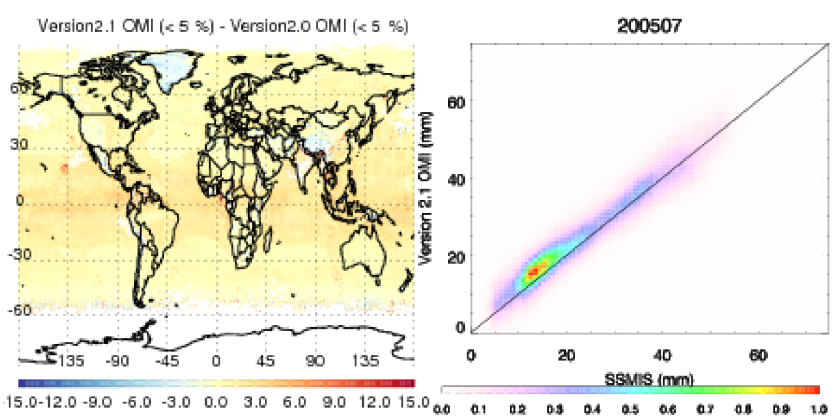

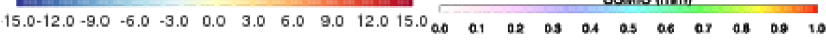

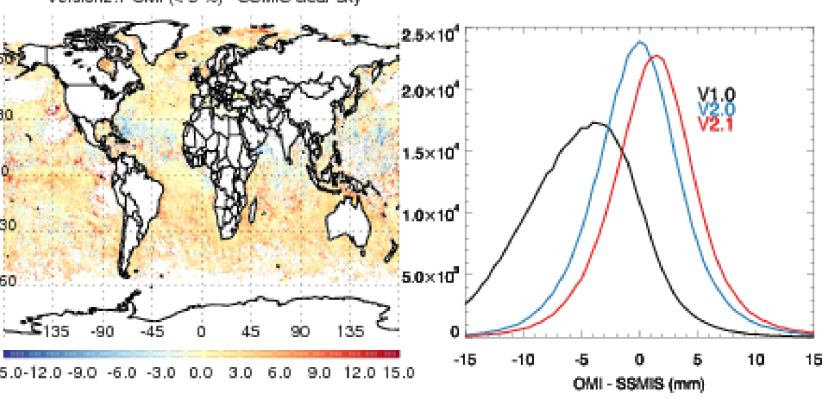

Figure 12. Top left: version 2.1-version 2.0 monthly mean OMI with cloud fraction $<5 \%$ for July 2005 . The other three panels are composed using coincident daily gridded $\left(0.5^{\circ} \times 0.5^{\circ}\right)$ OMI (with cloud fraction $<5 \%$ ) and "clear" sky SSMIS data for July 2005. Bottom left: monthly mean of version 2.1 OMI-SSMIS. (Top right) 2-D normalized histogram of version 2.1 OMI vs. SSMIS composed using $0.5 \mathrm{~mm} \times 0.5 \mathrm{~mm}$ TCWV bins. Bottom right: histogram of version 1.0 OMI-SSMIS in black, version 2.0 OMI-SSMIS in blue, and version 2.1 OMI-SSMIS in red.

with the scattering weights interpolated from a look-up table (Wang et al., 2014). The look-up table was constructed using the radiative transfer model VLIDORT (Spurr, 2006). The scattering weights in the look-up table depend on surface pressure, surface albedo, solar zenith angle (SZA), view zenith angle (VZA), relative azimuth angle (RAA), ozone column amount, cloud fraction, cloud pressure, and wavelength.

The following updates have been made to the AMF calculation: (1) using higher resolution $\left(0.5^{\circ} \times 0.5^{\circ}\right)$ a priori water vapor profiles generated by the MERRA-2 project of the Global Modeling and Assimilation Office (GMAO); (2) using the MERRA-2 surface pressure instead of an estimate based on the surface topography and the 1976 US standard atmosphere; (3) reconstructing the look-up table with more reference points for surface albedo, cloud fraction and cloud pressure, so that the interpolated values are more accurate; (4) improving scattering weight parameterization with respect to RAA.; (5) using simultaneously fitted ozone amounts in scattering weight calculations. We will refer to the algorithm with both these AMF updates and the SCD update described in Sect. 4.1 as version 2.1.

We have retrieved TCWV using the version 2.1 algorithm for July and January 2005. Figure 12 shows the result for 

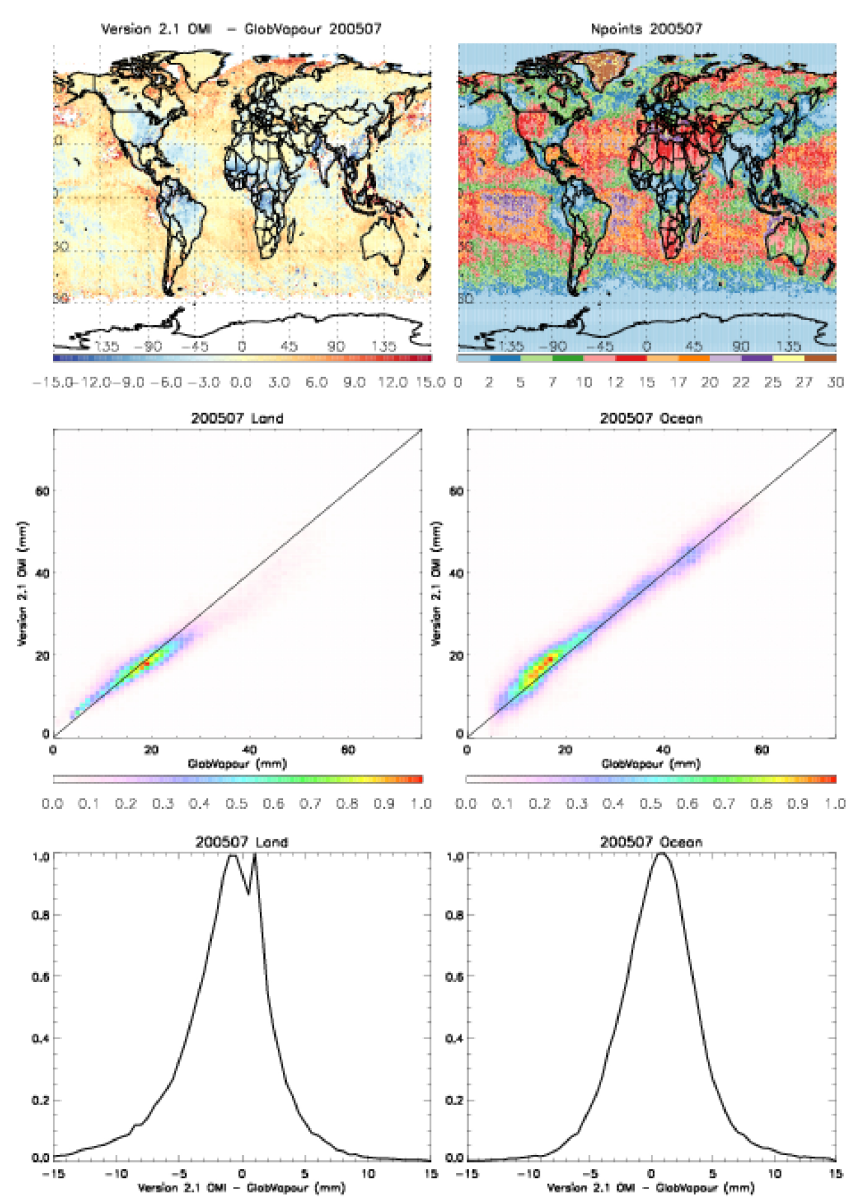

Figure 13. Comparison between version $2.1 \mathrm{OMI}$ (with cloud fraction $<5 \%)$ and GlobVapour data $\left(1^{\circ} \times 1^{\circ}\right)$ for July 2005. All panels are composed using coincident daily gridded data. Top left: monthly mean of OMI-GlobVapour. White areas represent missing data. Top right: number of coincident data points per pixel. Middle row: 2-D normalized histograms of version 2.1 OMI vs. GlobVapour for (left) land and (right) ocean. Bottom row: histograms of version 2.1 OMI-GlobVapour for (left) land and (right) ocean.

July 2005. The OMI data used here correspond to a $5 \%$ cloud fraction cutoff. The top left panel shows the monthly mean difference between version 2.1 and version 2.0 OMI data. The difference results from the AMF updates described above. Version 2.1 is about $3-5 \mathrm{~mm}$ higher than version 2.0 in the tropics, 3-5 mm lower over high topography, and almost unchanged in other areas. The bottom left panel shows the monthly mean of version 2.1 OMI-"clear" sky SSMIS. It is calculated using the same method as that for the bottom right panel of Fig. 11. Comparing the two, we find a further reduction of the low bias over the tropical oceans. In fact, the majority of the version 2.1 OMI data between 0 and $30^{\circ} \mathrm{N}$ are now within $\pm 3 \mathrm{~mm}$ of the "clear" sky SSMIS data. The bottom right panel shows the histograms of OMI-"clear" sky SSMIS for three versions of OMI retrievals. The mode of the distribution shifts from $-4.0 \mathrm{~mm}$ (version 1.0 ) through $0 \mathrm{~mm}$
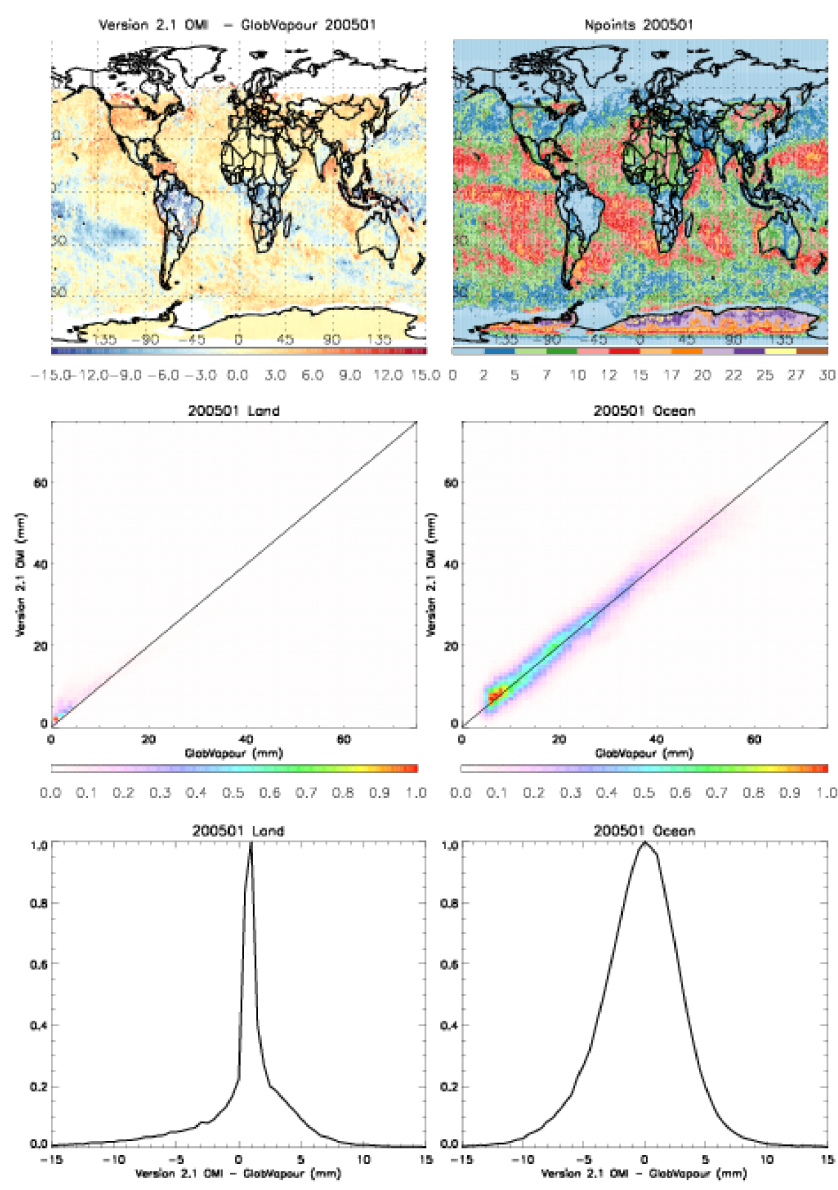

Figure 14. The same as Fig. 13 but for January 2005.

(version 2.0) to $1.5 \mathrm{~mm}$ (version 2.1). The top right panel of Fig. 12 shows the 2-D normalized histogram of version 2.1 OMI vs. SSMIS "clear" sky data. The slope is close to 1, but OMI is higher by about $1.5 \mathrm{~mm}$, which is consistent with the result shown in the bottom right panel.

In Figs. 13 and 14, we compare the version 2.1 OMI data with the GlobVapour MERIS + SSM/I data for July and January 2005, respectively. The top left panel shows the monthly mean of OMI-GlobVapour. It is calculated as the average of coincident daily gridded Level 3 data within the month. The OMI daily data are gridded with a $5 \%$ cloud fraction cutoff to represent "clear" sky conditions. Note that GlobVapour's land data (MERIS) are for clear sky conditions, but its ocean data (SSMIS) are for all sky conditions. There are usually about 10-20 coincident data points/pixel in the low latitudes (upper right panel). The differences between OMI and GlobVapour are generally within $\pm 6 \mathrm{~mm}$. Among them, large differences are typically located in the areas where few data points exist, such as northern South America, central Africa, eastern USA, China, and the Pacific Rim in July. In areas with good statistics, the differences are largely confined to within $\pm 3 \mathrm{~mm}$. The 2-D normalized histograms of OMI vs. 
GlobVapour are shown in the middle row for land (left) and ocean (right). The two data sets follow each other well. Over the ocean, OMI data are slightly higher than GlobVapour's SSMIS data (by about $1 \mathrm{~mm}$ ) in July and agree with GlobVapour's SSMIS data in January. Over land, OMI data are slightly higher than GlobVapour's MERIS data when TCWV is $<15 \mathrm{~mm}$ and slightly lower when TCWV is $>15 \mathrm{~mm}$. The normalized histograms of OMI-GlobVapour are shown in the bottom row for land (left) and ocean (right). The distributions show that OMI agrees with GlobVapour within $\pm 1 \mathrm{~mm}$ for both land and ocean and for both July and January. The FWHM of the histogram in July is $6 \mathrm{~mm}$ for both land and ocean, and that in January is $6 \mathrm{~mm}$ for ocean and $1 \mathrm{~mm}$ for land.

\section{Summary}

The AVDC collection 3 OMI TCWV data generated with the version 1.0 algorithm are compared with the NCAR's ground-based GPS network observations, AERONET's sunphotometer observations, and RSS's SSMIS microwave observations. Results show that the AVDC OMI data track the seasonal and interannual variability of TCWV for a wide range of climate regimes. The version 1.0 OMI data agree well with other data sets over land but show significant low biases over the ocean. Over land, for all the available co-located data from January 2005 to December 2009, OMI-GPS has a mean of $-0.3 \mathrm{~mm}$ and a median of $-0.4 \mathrm{~mm}$, and OMI-AERONET has a mean of $0 \mathrm{~mm}$ and a median of $-0.3 \mathrm{~mm}$. Although OMI-GPS or AERONET over land is larger in June-November than in DecemberApril, even the largest mean difference is between -1 and $0 \mathrm{~mm}$. In comparison, over the ocean, the version 1.0 OMI data (with cloud fraction $<5 \%$ ) are on average lower than the "clear" sky SSMIS data by about $4.7 \mathrm{~mm}$ in July 2005 and by about $6.5 \mathrm{~mm}$ in January 2005. The OMI low bias can be greater than $10 \mathrm{~mm}$ over the western Pacific and Atlantic in July and over the southern ocean in January. Clouds usually lead to large overestimates of OMI TCWV. As a result, the OMI data with cloud fraction $<25 \%$ are significantly higher than the all sky SSMIS data in areas with persistent cloud cover. We therefore do not recommend using OMI data that are affected by clouds.

By reducing the retrieval window length from 430-480 to $427.7-465.0 \mathrm{~nm}$ and using the water vapor reference spectra at the sea level, the version 2.0 OMI algorithm can significantly increase the retrieved TCWV over the ocean without affecting those over land much, leading to better agreements with the reference data sets. For July 2005, the offset between the version 2.0 OMI data (with cloud fraction $<5 \%$ ) and the "clear" sky SSMIS data over the western Pacific and Atlantic is reduced by more than half, and the global mean difference over the ocean improves to $0.1 \mathrm{~mm}$.
By updating the AMF calculations (Sect. 4.2) in addition to the SCD fitting, for July 2005 the version 2.1 retrieval algorithm leads to a further reduction of the version 2.0 OMI low bias in the western Pacific and Atlantic and the mean of version 2.1 OMI- "clear" sky SSMIS becomes $1.5 \mathrm{~mm}$. The version 2.1 OMI data agree with GlobVapour's MERIS + SSM/I data within $\pm 1 \mathrm{~mm}$ for both land and ocean and for both July and January 2005, although the distribution's FWHM is $6 \mathrm{~mm}$.

\section{Data availability}

The collection 3 version 1.0 OMI TCWV product from 2005 to 2009 is available at AVDC's website: http://avdc. gsfc.nasa.gov/index.php?site $=1389025893 \& i d=87$. The collection 3 version 2.1 OMI TCWV data will be released through AVDC once the entire archive is generated. NCAR's ground-based GPS data used in this paper are available at http://rda.ucar.edu/datasets/ds721. 1/. AERONET's sun-photometer data used in this paper are available at http://aeronet.gsfc.nasa.gov/cgi-bin/ combined_data_access_new. RSS's SSMIS data used in this paper are available at ftp://ftp.ssmi.com/ssmi/f16/ bmaps_v07/. GlobVapour's MERIS + SSM/I data are available at ftp://ftp-cmsaf-projects.dwd.de/ESA_GlobVapour/ External/Products/SSMI_MERIS/v1.0/.

Acknowledgements. This paper is supported by NASA's Atmospheric Composition: Aura Science Team program (sponsor contract number NNX14AF56G). We thank NASA's Aura Validation Data Center (http://avdc.gsfc.nasa.gov) for generating and archiving OMI water vapor product. The GPS precipitable water data are downloaded from http://rda.ucar.edu/datasets/ds721.1. The AERONET version 2 total column water vapor data are downloaded from http://aeronet.gsfc.nasa.gov/cgi-bin/combined_data_access_new. The SSMIS data are produced by Remote Sensing Systems (RSS), sponsored by the NASA Earth Science MEaSUREs Program and are available at ftp://ftp.ssmi.com/ssmi/f16/bmaps_v07/. The GlobVapour MERIS + SSM/I data are downloaded from ftp://ftp-cmsaf-projects.dwd.de/ESA_GlobVapour/External/ Products/SSMI_MERIS/v1.0/.

Edited by: V. Sofieva

Reviewed by: two anonymous referees

\section{References}

Acarreta, J. R., De Haan, J. F., and Stammes, P.: Cloud pressure retrieval using the $\mathrm{O}_{2}-\mathrm{O}_{2}$ absorption band at $477 \mathrm{~nm}$, J. Geophys. Res., 109, D05204, doi:10.1029/2003JD003915, 2004.

Bedka, S., Knuteson, R., Revercomb, H., Tobin, D., and Turner, D.: An assessment of the absolute accuracy of the Atmospheric Infrared Sounder v5 precipitable water vapor product 
at tropical, midlatitude, and arctic ground-truth sites: September 2002 through August 2008, J. Geophys. Res., 115, D17310, doi:10.1029/2009JD013139, 2010.

Bojkov, B.: ESA DUE GLOBVAPOUR product validation report, Combined SSMI + MERIS, Doc GlobVapour_D19_PVR_SSMI_MERIS_V3.1, 21 August 2012.

Diedrich, H., Preusker, R., Lindstrot, R., and Fischer, J.: Retrieval of daytime total columnar water vapour from MODIS measurements over land surfaces, Atmos. Meas. Tech., 8, 823-836, doi:10.5194/amt-8-823-2015, 2015.

Grossi, M., Valks, P., Loyola, D., Aberle, B., Slijkhuis, S., Wagner, T., Beirle, S., and Lang, R.: Total column water vapour measurements from GOME-2 MetOp-A and MetOp-B, Atmos. Meas. Tech., 8, 1111-1133, doi:10.5194/amt-8-1111-2015, 2015.

EOL/NCAR/UCAR (Earth Observing Laboratory/National Center for Atmospheric Research/University Corporation for Atmospheric Research): NCAR Global, 2-hourly Ground-Based GPS Precipitable Water, Research Data Archive at the National Center for Atmospheric Research, Computational and Information Systems Laboratory, updated yearly, available at: http://rda.ucar.edu/ datasets/ds721.1/ (last access: December 2015), 2011.

Holben, B. N., Eck, T. F., Slutsker, I., Tanre, D., Buis, J. P., Setzer, A., Vermote, E., Reagan, J. A., Kaufman, Y. J., Nakajima, T., Lavenu, F., Jankowiak, I., and Smirnov, A.: AERONET - A federated instrument network and data archive for aerosol characterization, Remote Sens. Environ., 66, 1-16, doi:10.1016/S00344257(98)00031-5, 1998.

Kishore, P., Ratnam, M. V., Namboothiri, S. P., Velicogna, I., Basha, G., Jiang, J. H., Igarashi, K., Rao, S. V. B., and Sivakumar, V.: Global $\left(50^{\circ} \mathrm{S}-50^{\circ} \mathrm{N}\right)$ distribution of water vapor observed by COSMIC GPS RO: Comparison with GPS radiosonde, NCEP, ERA-Interim, and JRA-25, J. Atmos. Sol.-Terr. Phy., 73, 18491860, 2011.

Kleipool, Q. L., Dobber, M. R., de Haan, J. F., and Levelt, P. F.: Earth surface reflectance climatology from three years of OMI data, J. Geophys. Res., 113, D18308, doi:10.1029/2008JD010290, 2008.

Lampel, J., Pöhler, D., Tschritter, J., Frieß, U., and Platt, U.: On the relative absorption strengths of water vapour in the blue wavelength range, Atmos. Meas. Tech., 8, 4329-4346, doi:10.5194/amt-8-4329-2015, 2015.

Lang, R., Casadio, S., Maurellis, A. N., and Lawrence, M. G.: Evaluation of the GOME water vapor climatology 1995-2002, J. Geophys. Res., 112, D17110, doi:10.1029/2006JD008246, 2007.

Levelt, P. F., van den Oord, G. H. J., Dobber, M. R., Malkki, A., Visser, H., de Vries, J., Stammes, P., Lundell, J. O. V., and Saari, H.: The Ozone Monitoring Instrument, IEEE T. Geosci. Remote, 44, 1093-1101, 2006.

Lindstrot, R., Preusker, R., Diedrich, H., Doppler, L., Bennartz, R., and Fischer, J.: 1D-Var retrieval of daytime total columnar water vapour from MERIS measurements, Atmos. Meas. Tech., 5, 631646, doi:10.5194/amt-5-631-2012, 2012.

Mears, C., Wang, J., Smith, D., and Wentz, F.: Intercomparison of total precipitable water measurements made by satellite-borne microwave radiometers and ground-based GPS instruments, J. Geophys. Res.-Atmos., 120, 2492-2504, doi:10.1002/2014JD022694, 2015.

Noël, S., Buchwitz, M., Bovensmann, H., and Burrows, J. P.: Validation of SCIAMACHY AMC-DOAS water vapour columns,
Atmos. Chem. Phys., 5, 1835-1841, doi:10.5194/acp-5-18352005, 2005.

Pérez-Ramírez, D., Whiteman, D.N., Smirnov, A., Lyamani, H., Holben, B.N., Pinker, R., Andrade, M., and AladosArboledas, L.: Evaluation of AERONET precipitable water vapor versus microwave radiometry, GPS, and radiosondes at ARM sites, J. Geophys. Res.-Atmos., 119, 9596-9613, doi:10.1002/2014JD021730, 2014.

Pougatchev, N., August, T., Calbet, X., Hultberg, T., Oduleye, O., Schlüssel, P., Stiller, B., Germain, K. St., and Bingham, G.: IASI temperature and water vapor retrievals - error assessment and validation, Atmos. Chem. Phys., 9, 6453-6458, doi:10.5194/acp9-6453-2009, 2009.

Pope, R. M. and Fry, E. S.: Absorption spectrum (380-700 nm) of pure water. 2. Integrating cavity measurements, Appl. Optics, 36, 8710-8723, doi:10.1364/AO.36.008710, 1997.

Rothman, L. S., Gordon, I. E., Barbe, A., Benner, D. C., Bernath, P. F., Birk, M., Boudon, V., Brown, L. R., Campargue, A., Champion, J.-P., Chance, K., Coudert, L. H., Dana, V., Devi, V. M., Fally, S., Flaud, J. M., Gamache, R. R., Goldman, A., Jacquemart, D., Lacome, N., Lafferty, W. J., Mandin, J. Y., Massie, S. T., Mikhailenko, S. N., Miller, C. E., Moazzen-Ahmadi, N., Naumenko, O. V., Nikitin, A. V., Orphal, J., Perevalov, V. I., Perrin, A., Predoi-Cross, A., Rinsland, C. P., Rotger, M., Simeckova, M., Smith, M. A. H., Sung, K., Tashkun, S. A., Tennyson, J., Toth, R. A., Vandaele, A. C., and Vander Auwera, J.: The HITRAN 2008 molecular spectroscopic database, J. Quant. Spectrosc. Ra., 110, 533-572, 2009.

Schlüssel, P. and Emery, W. J.: Atmospheric water vapour over oceans from SSM/I measurements, Int. J. Remote Sens., 11, 753766, doi:10.1080/01431169008955055, 1990.

Schrijver, H., Gloudemans, A. M. S., Frankenberg, C., and Aben, I.: Water vapour total columns from SCIAMACHY spectra in the $2.36 \mu \mathrm{m}$ window, Atmos. Meas. Tech., 2, 561-571, doi:10.5194/amt-2-561-2009, 2009.

Seemann, S. W., Menzel, W. P., and Gumley, L. E.: Operational retrieval of atmospheric temperature, moister, ad ozone from MODIS infrared radiances, J. Appl. Meteorol., 42, 1072-1091, doi:10.1175/1520-0450(2003)042<1072:OROATM>2.0.CO;2, 2003.

Sibylle, V., Dietrich, R., Rülke, A., and Fritsche, M.: Validation of precipitable water vapor within the NCEP/DOE reanalysis using global GPS observations from one decade, J. Climate, 23, 16751695, doi:10.1175/2009JCLI2787.1, 2010.

Smirnov, A., Holben, B. N., Eck, T. F., Dubovik, O., and Slutsker, I.: Cloud-screening and quality control algorithms for the AERONET database, Remote Sens. Environ., 73, 337-349, doi:10.1016/S0034-4257(00)00109-7, 2000.

Spurr, R. J. D.: VLIDORT: a linearized pseudo-spherical vector discrete ordinate code for forward model and retrieval studies in multilayer multiple scattering media, J. Quant. Spectrosc. Ra., 102, 316-342, doi:10.1016/j.jqsrt.2006.05.005, 2006.

Stammes, P., Sneep, M., de Haan, J. F., Veefkind, J. P., Wang, P., and Levelt, P. F.: Effective cloud fractions from Ozone Monitoring Instrument: Theoretical framework and validation, J. Geophys. Res., 113, D16S38, doi:10.1029/2007JD008820, 2008.

Thalman, R. and Volkamer, R.: Temperature dependent absorption cross-sections of $\mathrm{O}_{2}-\mathrm{O}_{2}$ collision pairs between 340 and $630 \mathrm{~nm}$ 
and at atmospherically relevant pressure, Phys. Chem. Chem. Phys., 15, 15371-15381, doi:10.1039/c3cp50968k, 2013.

Wagner, T., Heland, J., Zöger, M., and Platt, U.: A fast $\mathrm{H}_{2} \mathrm{O}$ total column density product from GOME - Validation with insitu aircraft measurements, Atmos. Chem. Phys., 3, 651-663, doi:10.5194/acp-3-651-2003, 2003.

Wagner, T., Beirle, S., Sihler, H., and Mies, K.: A feasibility study for the retrieval of the total column precipitable water vapour from satellite observations in the blue spectral range, Atmos. Meas. Tech., 6, 2593-2605, doi:10.5194/amt-6-2593-2013, 2013.

Wang, J. and Zhang, L.: Systematic errors in global radiosonde precipitable water data from comparisons with ground-based GPS measurements, J. Climate, 21, 2218-2238, doi:10.1175/2007JCLI1944.1, 2008.
Wang, J., Zhang, L., Dai, A., Van Hove, T., and Van Baelen, J.: A near-global, 2-hourly data set of atmospheric precipitable water from ground-based GPS measurements, J. Geophys. Res., 112, D11107, doi:10.1029/2006JD007529, 2007.

Wang, H., Liu, X., Chance, K., González Abad, G., and Chan Miller, C.: Water vapor retrieval from OMI visible spectra, Atmos. Meas. Tech., 7, 1901-1913, doi:10.5194/amt-7-1901-2014, 2014.

Wentz, F. J.: A well-calibrated ocean algorithm for special sensor microwave/imager, J. Geophys. Res., 102, 8703-8718, 1997.

Wentz, F. J., Hilburn, K. A., and Smith, D. K.: Remote Sensing Systems DMSP SSM/I Daily and Monthly Environmental Suite on $0.25^{\circ}$ grid, Version 7 , Remote Sensing Systems, Santa Rosa, CA, available at: http://www.remss.com/missions/ssmi (last access: December 2015), 2012. 